\title{
QUEM É O APRENDIZ DE TRADUÇÃO?
}

\section{Guilherme Fromm ${ }^{1}$}

RESUMO: Este texto pretende levantar, de modo sucinto, algumas discussões sobre os aprendizes de Tradução e os cursos para eles disponiveis no Brasil e no mundo. O artigo discute, também, questões pertinentes ao aprendizado da tradução, especialmente o aprendizado de Terminologia, bem como o mercado para aqueles que estão começando a vida profissional.

PALAVRAS-CHAVE: Tradução; Terminologia; Aprendizado de Tradução; Mercado de Trabalho.

ABSTRACT: This text intends to show, briefly, some discussions about Translation learners and the courses available to them in Brazil and around the world. The article also discusses questions about the Translation learning, especially concerning about Terminology and the market for those who are starting their careers.

KEYWORDS: Translation; Terminology; Translation Learning; Working Market.

\section{Introdução}

Com vários cursos de Tradução sendo oferecidos país afora, algumas considerações devem ser feitas sobre os aprendizes da área. Através de uma revisão bibliográfica discutem-se ques-

1 Doutor em Lingua Inglesa pela FFLCH/USP. Professor adjunto do ILEEL/ UFU.

TRadTerm, 16, 2010, p. 119-128 
tões como: quem é esse público? Quais são seus objetivos com o curso de Tradução? Quais habilidades eles já dominam para fazer uma tradução? Há outras habilidades que precisam ser trabalhadas? Quais? Eles têm conhecimento de ferramentas (como dicionários eletrônicos, vocabulários online, memórias de tradução) disponíveis para os profissionais? Não existe uma receita pronta que solucione qualquer uma dessas questões e que resolva problemas institucionais de ensino e aprendizado da arte de traduzir; mas uma discussão inicial deve ser posta e é isso que pretendemos com esse artigo.

\section{2. $O$ aprendiz de tradução}

Milton (2000) levanta uma série de questões referentes aos cursos de Tradução no Brasil e seus respectivos alunos, e muitas dessas questões são por nós vivenciadas quando atuamos como professores na área. O curso de Tradução é, de modo geral (embora não seja regra), ligado à área de Letras Modernas (em que estão presentes as línguas alemã, francesa, italiana, espanhola e inglesa), e isso pode indicar um perfil do egresso: muitos alunos parecem escolher o curso de Tradução como uma forma de melhorar suas habilidades linguísticas na língua desejada a fim de melhor ministrarem aulas; outros buscam uma nova fonte de renda, já que o curso os habilita para uma nova profissão e as escolhas nas grandes áreas de Letras e Linguística se resumem, cada vez mais, ao ensino, o que é compativel com seus interesses.

Concomitantemente, a quantidade de alunos matriculados no ensino superior, no Brasil, também tende, nos últimos anos, num processo contínuo, a se deslocar do eixo público para o privado, como atestam os dados do Censo da Educação Superior, coletados pelo $\mathrm{INEP}^{2}$ em 2008. Por paradoxal que seja, à medida que as faculdades/universidades privadas aumentam suas ofertas de vagas, não têm o mesmo compromisso que as públicas com a pesquisa.

2 Dados disponiveis em: http://www.inep.gov.br/imprensa/noticias/censo/superior/news09_05.htm.

TradTerm, 16, 2010, p. 119-128 
Essa falta de compromisso se reflete, também, nos cursos de Tradução e seus currículos. No caso dos currículos, ainda há uma lacuna sobre a organização dos mesmos nesses cursos superiores. Essa preocupação é comum aos pesquisadores da área (que se concentram, como se pode atestar pelas publicações em revistas especializadas, nas universidades públicas) tanto no Brasil quanto no exterior, como bem demonstram alguns textos de Pym (1993; 2002). O que o aluno de Tradução, então, deveria ter como base de seu currículo?

Para o início da discussão, devemos atentar ao panorama que Milton (2000:83-105) traçou das possibilidades de formação de tradutores Brasil. Existem aqueles que fazem uma graduação:

a. em uma área qualquer e depois partem para um curso de especialização em Tradução;

b. em uma área qualquer e depois participam de vários cursos de curta duração em Tradução;

c. em Tradução.

Ainda que possam dominar áreas técnicas específicas, os alunos dos casos $a$ e $b$, portanto, podem chegar aos cursos com uma formação linguística deficiente. Será que as possiveis deficiências serão sanadas por cursos de Tradução?

\section{O Ensino da Tradução no Brasil e no mundo}

Alguns pesquisadores, entre eles Gonçalves e Machado (2006), vem se preocupando com a questão do ensino da Tradução no Brasil. Schäffner e $\mathrm{Adab}^{3}$ (2000), refletindo sobre o ensino de Tradução na Europa, indicam que

(...) diferentes tipos de instituições acadêmicas oferecem cursos para a formação profissional. Dependendo de restrições sócio-culturais, seus currículos e programas po-

3 SCHÄFFNER, C.; ADAB, B. (2000) Developing translation competence. Amsterdam: John Benjamins Publishing.

TradTerm, 16, 2010, p. 119-128 
dem priorizar a teoria de tradução, habilidades práticas e, mais freqüentemente, uma combinação de ambas. (Schäffner e Adab, 2000 apud Gonçalves \& Machado, 2006:46. Tradução de Gonçalves \& Machado)

Isso acaba polarizando os cursos, segundo Gonçalves e Machado, entre o treinamento prático (automatização/desenvolvimento de conhecimentos procedimentais - saber como) e a reflexão teórica (conscientização/desenvolvimento de conhecimentos declarativos - saber o quê), quando da discussão sobre a construção daquilo que denominam Competência do Tradutor (CT). Essa discussão começa a ser levantada no Brasil também. Os autores identificaram, entre graduação e especialização, cento e dezoito instituições que oferecem cursos de Tradução no Brasil.

Apesar do grande número de cursos, uma questão pode ser levantada: será que esses futuros profissionais estão preparados para lidar com as necessidades do mercado de Tradução? Os currículos dos cursos os preparam de modo satisfatório para exercerem sua profissão? Pym (1993; 2002; 2006) dá uma resposta negativa para ambas as perguntas. O aprendiz, a princípio, está ali para burilar seus conhecimentos na língua de partida (o inglês, por exemplo) e melhorar sua redação na língua de chegada (português, no caso do Brasil). Os cursos, então, tentam atender a essa demanda e investem no aperfeiçoamento dos pares de línguas escolhidas. Porém, quanto é investido no aprendizado das ferramentas ligadas ao ato de traduzir? Como o mercado de trabalho é analisado em sala de aula? Terão os professores vivência suficiente na área de Tradução e no uso de ferramentas para repassar suas experiências aos alunos?

Como exemplo de cursos desenvolvidos no exterior que investem nessa vertente de aprendizado de ferramentas informatizadas, podemos citar as experiências coletadas por Jaatinen e Jääskeläinen (2006) durante o projeto Colc (Computing for Language Careers), que pretendia inserir a tecnologia da informação no treinamento de tradutores. Entre as disciplinas do currículo básico, estavam inclusas: introdução à localização, habilidades básicas de computação para tradutores, interfaces de uso gráfico, introdução à engenharia de software, documen- 
tação de software, ferramentas de memória de tradução e bancos de dados de termos, Linguística de Corpus e tradução assistida por corpus.

Araújo (2001), por outro lado, realizou um dos melhores estudos sobre cursos de Tradução no Brasil, inclusive com a análise de grades curriculares e ementas de disciplinas. Dentre as dez instituições analisadas que ministravam cursos de graduação ou especialização em Tradução, seis não contavam com disciplinas de Terminologia, base para o aprendizado de uso e criação de novas ferramentas para tradutores. Numa segunda fase de sua pesquisa, trabalhando apenas com alunos que cursaram a disciplina de Terminologia, a autora destaca, ao analisar a familiaridade desses alunos com recursos terminológicos, uma conclusão que remete ao pensamento de Pym sobre problemas no ensino de ferramentas informatizadas para aprendizes:

Neste grupo de respondentes, apenas 25\% mencionaram conhecer algum tipo de ferramenta terminológica para a tradução. Destes, 33\% apontaram conhecer bancos de dados, 27\% mencionaram estar familiarizados com glossários e 13\% mencionaram conhecem dicionários especializados. Apenas $27 \%$ desses alunos mencionaram conhecer um programa específico, o Autolex. (Araújo, 2001:61)

Essas e outras conclusões levantadas pela pesquisa da autora apenas corroboram a ideia de que há muito a ser discutido sobre o ensino de Tradução no Brasil, onde pouco espaço é dado ao aprendizado de ferramentas informatizadas de apoio ao profissional, ao mesmo tempo em que os tradutores experientes, na sua maioria, trabalham com textos técnicos que exigem o manuseio dessas ferramentas e o conhecimento da Terminologia das áreas a serem traduzidas ${ }^{4}$.

4 Outra pesquisa realizada por Araújo (2001:46), com firmas de tradução, revela que $82 \%$ da fatia do mercado de trabalho dos tradutores está nas áreas técnicas.

TradTerm, 16, 2010, p. 119-128 


\section{4. $O$ aprendizado em tradução}

Diversos autores trabalham com a questão do ensino de Tradução. Começamos a discussão com aqueles que tratam de questões de caráter geral sobre o ensino e especificamos, mais adiante, autores diferentes que destacam outras questões pertinentes.

Arrojo (2003), por exemplo, propõe que aprender a traduzir é aprender a ler: "aprender a produzir significados, a partir de um determinado texto, que sejam 'aceitáveis' para a comunidade cultural da qual participa o leitor" (Arrojo, 2003:76). O bom tradutor seria, continua a autora, aquele que aprende então a ler, a escrever (com o mesmo cuidado daqueles que se preparam para serem escritores) e a se manter informado a respeito das teorias e dos estudos sobre tradução.

Já Stolze (1997), analisando indicadores de como avaliar uma tradução, repara que o ensino de tradução está frequentemente aliado ao ensino de língua. Segundo a autora, contudo, “(...) a proficiência linguística e o conhecimento do assunto são precondições para a tradução" (Stolze, 1997:165-166). Entre as categorias linguísticas descritas pela autora, destaca-se a questão do Léxico e da Terminologia (comunicação em áreas especializadas). A autora salienta que a didática da tradução deve destacar diferentes modos de terminologização a fim de sensibilizar o tradutor para as diferenças terminológicas e de constituição textual entre a área científica e a de humanidades (idem: 162).

A grande vertente atual de discussão entre os estudiosos, no entanto, caminha em direção à chamada Competência Tradutória. Gonçalves e Machado (2006), nesse sentido, levantam dezessete categorias de Competência defendidas por vários teóricos, apontando o quanto elas são adotadas, em questão de porcentagem, pelas instituições de ensino. Essas categorias de competência foram agrupadas num gráfico (Figura 1), em que se pode comprovar que duas das competências, particularmente, são bastante relevantes para esta discussão: a questão da Terminologia (item 8 do gráfico) e das Tecnologias que podem ser aplicadas à tradução (item 12 do gráfico).

A Terminologia é uma das bases para a construção de um bom texto. Nem todos os dicionários bilíngues fornecem infor- 
mações suficientes para que o tradutor esclareça suas dúvidas. Aprender a descobrir e criar novos termos, assim, também deve fazer parte do aprendizado. Note-se que apenas $41,3 \%$ dos cursos investem, em algum momento, no aprendizado de Terminologia. A nosso ver, o índice deveria ser de $100 \%$.

$\mathrm{Na}$ verdade, o ensino das novas tecnologias requer, por parte das universidades e cursos livres, um alto investimento em computadores, programas (especialmente dicionários eletrônicos, memória de tradução e análise de corpora) e acesso à Internet (e às bases linguísticas). Traduzir sem computador, como bem observou Gil e Pym (2006), é um anacronismo:

Tecnologia não é uma opção no mundo profissional hoje em dia; é uma necessidade. Anos atrás se falava de Tradução Assistida por Computador (CAT). Isso, agora, parece redundante. Virtualmente todas as traduções são assistidas por computador. ${ }^{5}$ (Gil\&Pym, 2006:17. Tradução do autor)

O índice de apenas $55,1 \%$ de instituições que se dedicam ao ensino de novas tecnologias aplicadas à Tradução é, portanto, inadmissivel. Traduzir usando como ferramentas apenas dicionários desatualizados é uma prática completamente fora de seu tempo. O aluno que frequenta cursos que não investem na tecnologia estará, fatalmente, com seu aprendizado prejudicado.

5 “Technology is not an option in today's professional world; it is a necessity. Years ago one talked about Computer-Aided Translation (CAT). That now seems a redundancy. Virtually all translating is aided by computers."

TradTerm, 16, 2010, p. 119-128 


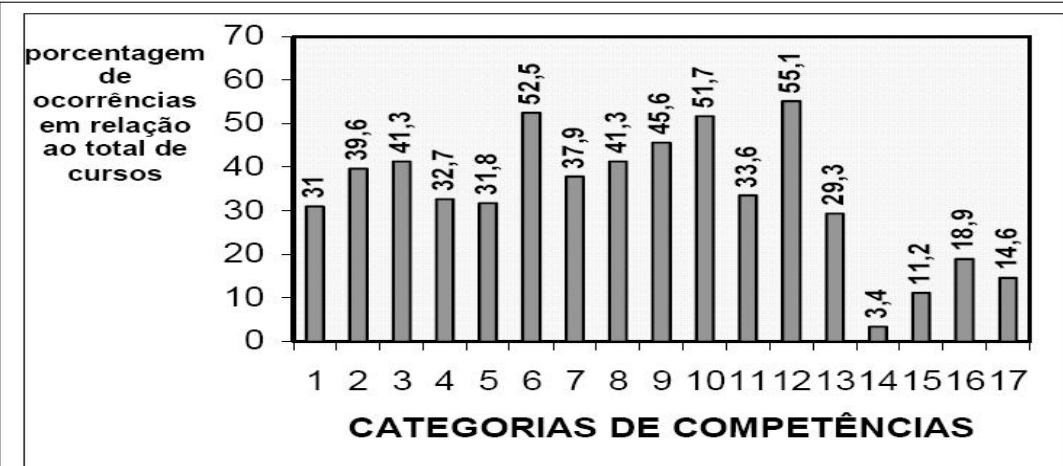

Competência lingüística na língua materna

Competência linguística prévia na(s) língua(s) estrangeira(s)

Competência lingüística a ser desenvolvida na(s) língua(s) estrangeira(s)

Competência pragmática e sociolingüística na língua materna

Competência pragmática e sociolingüística na(s) língua(s) estrangeiras(s)

Conhecimento de ambas as culturas das línguas de trabalho

Conhecimentos temáticos

Terminologia

Conhecimentos declarativos sobre tradução

10. Conhecimento relacionado à prática profissional

11. Conhecimentos relacionados ao uso de fontes de documentação

12. Tecnologias que podem ser aplicadas à tradução

13. Conhecimentos operativos/ procedimentais sobre tradução

14. Aspectos cognitivos

15. Aspectos meta-cognitivos

16. Conhecimentos contrastivos

17. Aspectos emocionais/subjetivos

Figura 1: Competências Tradutórias trabalhadas nos diversos cursos de Tradução no Brasil (Gonçalves \& Machado, 2006)

A questão da competência também é trabalhada por Alves (1997), que divide a questão da aprendizagem entre Competência Linguística e Competência Tradutória. O autor indica que a Competência Linguística é algo que deveria ser inerente ao aprendiz (em consonância com a opinião de Stolze (1997), quando fala de proficiência linguística); o que deve ser desenvolvido é a sua Competência Tradutória. Alves defende, na busca da conscientização do tradutor nos passos do oficio, a existência de duas etapas da Competência Tradutória: o Bloco Adhoc (composto por automatismos) e o Bloco Restante (dividido em seis passos: bloqueio processual; apoio interno; apoio externo; a combinação de apoios interno e externo; priorização e omissão de informações e burilamento final do texto de chegada). O Bloco Adhoc representa o conhecimento prévio que o aluno já dispõe e pelo qual não 
há necessidade de reflexão frente às questões tradutórias. O Bloco Restante indica os passos seguintes ao primeiro bloco, pois dificilmente um texto apresenta tanta facilidade que se possa traduzi-lo sem ter dúvidas, sem precisar de materiais extras, sem priorizar ou emitir informações e sem dar um retoque final à tradução.

\section{Considerações Finais}

Ao contrário do que muitos pensam, traduzir não é entregar um texto ao tradutor (muitas vezes considerado uma ferramenta de tradução automatizada, como o Google Translate) e esperar que a tradução seja feita imediatamente. Traduzir exige conhecimento de ambas as línguas (partida e chegada), um bom processo de aprendizado e o uso das últimas ferramentas disponíveis no mercado. A imagem do tradutor em frente à máquina de escrever e cercado de dicionários por todos os lados é algo que não mais existe. $O$ aprendiz (seja da faculdade pública, seja da privada) deve ter em mente que, sem investimento na sua educação e ferramentas de trabalho, o mercado pode deixá-lo(la) de lado a qualquer momento.

\section{Referências bibliográficas}

ALVES, F. (1997) A formação de tradutores a partir de uma abordagem cognitiva. TradTerm. São Paulo: Humanitas, n. 4.2.

ARAÚJO, L. A. (2001) De big-bangs a buracos negros no universo da tradução no Brasil: um estudo sobre o papel da terminologia na prática tradutória e na formação de tradutores. Campinas, Instituto de Estudos da Linguagem (IEL)/UNICAMP. Tese de Doutorado em Linguística Aplicada.

ARROJO, R. (2003) Oficina de tradução. São Paulo: Ática.

GONÇALVES, J.L.V.R.; MACHADO, I.T.N. (2006) Um panorama do ensino de tradução e a busca da competência do tradutor. Cadernos de Tradução. Santa Catarina: UFSC, n. 17.

GIL, J.R.B.; PYM, A. (s/d) Technology and translation (a pedagogical overview). Disponível em <http://www.tinet.org/ apym/on-line/

TradTerm, 16, 2010, p. 119-128 
translation/BiauPym_TechnologyAndTranslation.pdf $>$. Acesso em de 19 de julho de 2006.

JAATINEN, H.; JÄÄSKELÄINEN, R. (2006) Introducing IT in translator training: experiences from the COLC project. PYM, A., PEREKRESTENKO A., STARINK B. (org.). Translation Technology and its teaching. Tarragona: Servei de Publicacions. Disponivel em <http://isg.urv.es/ library/papers/JaatinenJaaskelainen_IntroducingIT.pdf $>$. Acesso em 19 de julho de 2007.

MILTON, J. (2000) Por que estudantes brasileiros escolhem cursos de tradução? TradTerm, São Paulo: Humanitas, n. 6.

PYM, A. (1993) On the market as a factor in the training of translators. Koiné, $\mathrm{n}^{\circ}$ 3. Disponivel em <http://www.tinet.org/ apym/on-line/ translation/market.html>. Acesso em 19 de julho de 2007.

(2002) Redefining translation competence in an electronic age. In defence of a minimalist approach. Disponivel em <http://www.tinet. org/ apym/on-line/training/competence.pdf >. Acesso em 17 de julho de 2007.

(2006) Asymmetries in the teaching of translation technology. Translation Technology and its teaching. PYM, A., PEREKRESTENKO A., STARINK B. (org.). Tarragona: Servei de Publicacions. Disponivel em <http://www.tinet.org/ apym/on-line/training/Pym_Teaching Asymmetries.pdf $>$. Acesso em 19 de julho de 2007.

STOLZE, R. (1997) Indicadores de qualidade para a avaliação de traduções no âmbito da didática. TradTerm. São Paulo: Humanitas, n. 4.1.

TradTerm, 16, 2010, p. 119-128 